\title{
Kas on alust rääkida rahvuslikest subkultuuridest? ${ }^{1}$
}

\author{
Aimar Ventsel \\ Tartu Ülikooli etnoloogia vanemteadur \\ aimar.ventsel@ut.ee
}

\begin{abstract}
Teesid: Subkultuuride uurimise fookus on traditsiooniliselt aspektidel, mis eristavad neid peavooluühiskonnast. Sellest johtuvalt on rõhk olnud stiili, muusika, subkultuurispetsiifiliste praktikate ja ka kultuuriliste ja sotsiaalsete konfliktide uurimisel. Väga oluline on uurimustes glokaliseerumise kontseptsioon. See tähendab analüüsimist, kuidas globaalne subkultuur adapteeritakse konkreetsesse rahvuslikku raami. On olemas mitmeid uurimusi näiteks Lääne subkultuuride glokaliseerimisest/glokaliseerumisest moslemiühiskondades või ka Aafrika riikides. Mina seevastu väidan käesolevas artiklis, et glokaliseerumise fenomeni uurimises on tähelepanuta jäänud vastupidine tendents - viisid, kuidas rahvuslikke ja/või lokaalseid dominantühiskonna norme tuuakse subkultuuri ja muudetakse selleläbi subkultuuri iseloomu. Artikkel näitlikustab, kuidas subkultuursete stiilide paljusus toetab sellist vastupidist glokaliseerumist, pakkudes platvormi erinevatele sotsiaalsetele normidele, poliitilistele vaadetele ja identiteedikontseptsioonidele.
\end{abstract}

Märksõnad: glokaliseerumine, hiphop, identiteet, punk, skinheed, subkultuur, töölisklass

Subkultuurid ehk siis ala- või osakultuurid on peamiselt sotsioloogias omaette uurimisteema juba peaaegu sadakond aastat. Subkultuuride uurimine algas 1930. aastatel Chicago koolkonnaga, ehk siis sotsioloogidega, kes uurisid n-ö hälbelisi inimrühmi. Hälbelisus (deviancy) tähendas antud kontekstis, et uuriti USA “peavooluühiskonnast” erinevaid gruppe, ehk siis inimesi, kes ei olnud keskklassi valged ameeriklased. Peamine fookus sellel suunal oli kultuurikonfliktide uurimisel ehk lähenemisel, mida siis ja nüüd nimetati kultuuriökoloogiaks. Hea näide on Paul Goalby Cressey uurimus taksojuhtidest migrantide ja neid teenindavate prostituutide tantsuklubide kultuurist (Cressey 1932) või siis William Foote Whyte'i raamat itaalia kogukonna kriminaalsetest praktikatest (Whyte 1998). See vaateviis seadis suuna, ning Chicago koolkonnast kasvas välja kriminaalsete jõukude uurimise traditsioon (Bloch \& Niederhoffer 1958; Cohen 1955; Yablonsky 1962), millest tulenevalt seostatakse õigussotsioloogias 
tänapäevani hälbelisuse ja subkultuuri mõisteid valdavalt kuritegelike gruppidega (Gusfield 1995; Mullins 2006; Sampson \& Bartusch 1988; Wolfgang \& Ferracuti 1982). Õigussotsioloogilistes subkultuuriuuringutes on kahjuks väga väike roll kuritegelike subkultuuride kultuuri ja tarbimisharjumuste uurimisel, ehkki mitmed uurimused näitavad, et sellised jõugud on seotud ka kindlate muusika- ja riietumiseelistustega, ühesõnaga kõige sellega, mida nimetatakse nüüdisaegses käsitluses noorte subkultuurideks (youth subcultures) (vt nt Burt \& Simons 2013; Mullins 2006; Nayak 2003, 2006; Young 2013). Tänapäeva mõistes subkultuurile lähemale nihutas uurimissuunda Howard Becker (1997), kes alustas oma akadeemilist teed narkootikumide tarbimise uurimisega. Olles ise muusik, hakkas ta uurima mõnuainete tarbimist džässmuusikute hulgas ning leidis, et peale marihuaana tarbimise oli terve muusikute hoiakute ning praktikate maailm "hälbeline" ehk siis n-ö tavainimese maailmast erinev. Beckeri raamat oli üks neist inspireerivatest teostest, mis ajendas hälbelisust vaatama laiemalt ja mitte ainult kuritegevuse või etniliste vastuolude raames.

\section{Noorte subkultuuride uurimisest}

1980. aastad on aeg, mille puhul on alust rääkida noorte subkultuuride mõiste kujunemisest akadeemilistes uurimustes. Ajaloolises plaanis tekkis nähtus, mida eesti keeles nimetati kunagi noorteliikumiseks, alates 1990. aastast aga ka järjest rohkem noorte subkultuuriks (Allaste 2013). Ehkki sarnaseid nähtusi eksisteeris ka varem, eriti džäss- ja svingimuusika ümber (Savage 2007; Wallace \& Alt 2001), viis mitmete tegurite kokkusattumine noorte subkultuuride formeerumise pärast Teist maailmasõda hoopis teisele tasemele. Oluline oli siin tehnika areng, mis soosis noorte kui omaette tarbimisrühma teket. Johtuvalt üleminekust šellakplaatidelt vinüülplaatidele muutus muusika tarbimine eelkõige helikandjate ostmine - odavamaks ja edastatava heli kvaliteet paranes tuntavalt. Teine põhjus oli Teise maailmasõja järgne majanduskasv, mille tõttu briti töölisklassi noortel tekkis võimalus kulutada raha peale esmaste elatusvahendite ka erinevatele tarbimiskultuuri toodetele nagu muusikale, riietele, tehnikale ja meelelahutusele üldse. Noortele sai hakata turustama just neile suunatud moodi kui elustiili. Akadeemilises arusaamises, mida ka autor toetab, on enamik n-ö klassikalisi subkultuure pärit Suurbritanniast ja nende rida algab 1950. aastatel teddy boy stiiliga. Need olid valdavalt töölisklassi noored, kes hakkasid kopeerima kuningas Edward VII aegset glamuurset riietumisstiili, kombineerides seda USA vesternfilmide kauboi-ja Metsiku Lääne elukutseliste kaardimängurite riietumisstiiliga (Macilwee 2015). Oluliseks muutus teddy boy 
stiilile sel hetkel USAst maailmavallutamist alustanud rock'n'roll-muusika. Teddy boy'dest alguse saanult pääses valla noortekultuuride tekkimise laine, millega kaasnes iga mõne aasta järel muusikastiilide ja nendega seotud riietumisviiside uuenemine, ehk nähtus, mida akadeemilises kirjapruugis tuntakse homoloogiana - sideme tekkimisena konkreetse muusikastiili, selle fännide riietuse ning käitumisviisi vahel. Antud kultuurinähtuse juures on oluline roll tehnika arengul, mis muutis sellise kaasaegsete noorte subkultuuride tekkimise võimalikuks. 1950. aastatel võeti kasutusele vinüülplaadid, turule tulid uut tüüpi plaadimängijad, odavamaks muutus nii muusika lindistamine, plaatide tootmine kui ka seeläbi muusika tarbimine. See tegi võimalikuks asjaolu, et popmuusika muutus laialt kättesaadavaks ja seoses sellega noorte elus äärmiselt oluliseks (Brake 1985; Frith 1983, 1988, 2001; Marcus 1989).

Mitukümmend aastat pärast seda, kui Suurbritannia elanikke oli šokeerinud erinevate noortestiilide ilmumine (modernistid, skinheedid, rastad, pungid jne) ${ }^{2}$, hakkasid neid uurima Birminghami Ülikooli juures asutatud Kaasaegsete Kultuuride Uurimise Keskuse (Centre for Contemporary Cultural Studies) sotsioloogid. Seda koolkonda tuntakse subkultuuride teooria, Birminghami koolkonna või siis uurimisasutuse lühendi järgi ka CCCS koolkonnana. CCCS koolkond oli marksistlik ja selle üldine teoreetiline kontseptsioon on määratletav teatud postulaatidega. Esiteks väitsid koolkonna liikmed, et noorte subkultuurid tekivad töölisklassi sees ja väljendavad laiemaid ühiskondlikke konflikte. Siit edasi oli loogiline väita, et subkultuuri saab vaadata kui töölisklassi vastupanu dominantühiskonnale (ehk siis keskklassi poolt domineeritud väärtuste süsteemile ja elustiilile) rituaalse vastupanu abil. Rituaalideks olid subkultuuriti erinev elustiil, teistsugune välimus, kirglik muusika fännamine ning subkultuurispetsiifiliste käitumisviiside ja praktikate leiutamine. Lisaks sellele kuulus CCCS teoreetilise kontseptsiooni hulka väide, et noorte subkultuur põhineb näost näkku suhtlemisel väikese grupi sees. Hiljem subkultuur - ehk siis vastav riietumisstiil ja muusika - levib ning saavutab üha suurema populaarsuse, kuni mingil hetkel korjavad meedia ja kommertsstruktuurid antud stiili üles, muudavad selle turundusobjektiks, subkultuur väljub töölisklassi piiridest ja muutub kommertskultuuriks (Clarke \& Critcher \& Johnson 1979; Hall \& Jefferson 1986; Hebdige 1979, 1987; Willis 2000; Willis et al. 1990). CCCSi lähenemise üheks puuduseks oli see, et nad tegelesid vähe - kui üldse - empiirilise uurimistööga ning enamik nende publikatsioone ja raamatuid põhineb peamiselt sekundaarsetel allikatel, näiteks meediaväljaannete või siis laulutekstide analüüsil.

Subkultuuriteooriale tekkis 1990. aastatel vastukaaluks postsubkultuuriteooria ja antud koolkond on siiamaani noorte subkultuuride uuringutes domineeriv. Postsubkultuuriteooria seadis kõik eelneva koolkonna postulaadid 
kahtluse alla. Kõige enam kriitikat pälvis klassipositsiooni kriteerium. Postsubkultuuriteooria uurijad eitasid noortekultuuride põhjuslikku sidet töölisklassiga ning väitsid et klassitaust ei ole subkultuuride tekkel ega nendega ühinemisel oluline (Muggleton 2005, 2000; Muggleton \& Weinzierl 2003). See koolkond väidab, et noorte subkultuur pole seotud vastupanu või mässuga, vaid tegemist on puhtalt tarbimiskultuuriga, mille puhul stiil on lihtsalt tarbimiseelistuste väljend. Samuti seati kahtluse alla subkultuuriline identiteet kui selline. Subkultuur ei ole selles käsitluses kindlapiiriline - ja kindla identiteediga - grupp, vaid hägusate piiridega inimrühm, kus inimesed pidevalt tulevad ja lähevad ning välimust vahetavad (Muggleton 2000), teinekord aga üldse ei näe üksteist, vaid ühine grupiidentiteet luuakse ainult virtuaalruumis (Bennet 2004; Williams 2006). Seepärast kasutab postsubkultuuri koolkond subkultuuri asemel väljendeid nagu tribe, scene või neo-tribe (Bennet 2011; Hesmondhalgh 2005; Straw 2002). Subkultuuri akadeemilise mõiste muutumisega ilmus kasutusse kontseptsioon stiilide supermarketist (the supermarket of style) (Polhemus 1997). Stiilide supermarketi kontseptsiooni aluseks on idee, et subkultuuride maailm on nagu suur väljamüük: igaüks võib vastavalt oma soovile valida selle stiili, mis talle meeldib. Ted Polhemuse töödes torkab silma, et ta lahutab sotsiaalse grupiidentiteedi subkultuurilisest identiteedist - ta taandab stiilivaliku individuaalseks isikliku maitsega seotud aktiks, umbes nagu inimene valib tänavakohvikus erinevate jäätiste vahel.

Postsubkultuuriteooria suhtes on ilmunud hulgaliselt kriitikat. Peamiselt on kritiseeritud seda, et postsubkultuuriteooria eitab subkultuurilist identiteeti kui sellist, väites et tegemist on puhta tarbimiskultuuriga, millel pole sotsiaalset sisu, samuti postuleeritakse konkreetsete struktuuride ning grupisiseste hierarhiate puudumist. Nii osutab Shane Blackman (Blackman 2005), et ehkki David Muggleton (2000) üritab oma epohhiloova raamatuga "Inside Subculture" väita, et subkultuure kui konkreetse struktuuri ja identiteediga gruppe ei eksisteeri ehk subkultuuridel "pole enam reegleid" (there are no rules, lk 47), näitab Muggletoni raamatu empiiriline osa siiski selgesti, et isegi tema uuritud punk ja mod grupid alluvad enda kehtestatud reeglitele, küll aga võivad inimesed vahetada subkultuuri individuaalsel tasandil, kui üks stiil nende silmis ammendub (Blackman 2005: 10-11). Samal moel on kritiseeritud ka väidet, et klass kui sotsiaalne kategooria ei mängi enam subkultuuriliste identiteetide moodustamisel rolli. On uurimusi, milles näidatakse, et klass võib mõningate noorte subkultuuride juures siiski etendada tähtsat osa kui solidaarsuse ja eneseidentifikatsiooni alus (Nayak 2003; Shildrick 2006; Shildrick \& MacDonald 2006). Teine irooniline moment postsubkultuuriteooria juures on asjaolu, et mitmed uurijad, kes eitasid subkultuuri kui normide ja väärtuste süsteemi olemasolu, on hiljem rääkinud endale vastu, avaldades uurimusi, kus nad ana- 
lüüsivad, miks subkultuuri liikmed oma stiilile ka vananedes truuks jäävad, ja jõuavad järeldusele, et selle põhjuseks on subkultuuri maailmavaatel - ehk siis väärtussüsteemil ja reeglitel - põhinev elustiil (Bennett 2006; Davis 2012; Hodkinson 2011).

\section{Popkultuuri globaliseerumine}

Popkultuuri erinevad tahud, eriti muusika ja mood, on alati kiired levima. Raadio- ja plaadimuusika levik aitas enne Teist maailmasõda levida džässja svingmuusikal, tango sai tuule tiibadesse veel enne seda (Savigliano 1995; Wallace \& Alt 2001). Ülalpool mainitud tehnoloogia areng kiirendas popkultuuri(de) ja noortemoe levikut sõjajärgseil aastail aga veelgi. Kinost sai võimas meedium, mis transportis uusi stiile kaugetesse maadesse, ent ka raadio oli piisavalt oluline lüli välismaise muusika vahendamisel. Rock'n'roll, biitmuusika ja samuti tavaline estraad levisid kiiresti, jõudes kapitalistlikust läänemaailmast peaaegu välgukiirusel ka sotsialistlikku maailma. Seda, et raudne eesriie ei olnud piisavalt tihe, näitab kasvõi see, kui kiiresti jõudsid uued stiilid ja moenähtused Nõukogude Eestisse (Amico 2009; Garšnek 2010; Rinne 2009; Salumets 1998, 2010; Tõnson 1976; Vahter 2015). Peamiselt briti ja USA päritolu noortekultuuri nähtusi kopeeriti, võeti omaks, muudeti ka Eestis ja selle protsessi käigus kujunesid välja lokaalsed versioonid globaalsest angloameerika popkultuurist. Seda protsessi nimetatakse glokaliseerumiseks ning noorte- ja subkultuuride uuringutes on glokaliseerumist uuritud palju. Väga oluline fookus glokaliseerumise käsitlustes on sellel, kuidas ja miks võetakse üle angloameerika kultuurist pärit stiile kogu maailmas ning kuidas kohapeal konstrueeritakse võimalikult autentset USA või briti päritolu noortekultuuri. Üldjuhul vaatavad sellised uurimused, kuidas uuel asukohamaal luuakse oma versioon subkultuuridest nagu näiteks punk, klubikultuur, hiphop või metal ja kuidas ning millega põhjendatakse seda, et lokaalne versioon globaalsest kultuurinähtusest on "päris" ehk "autentne", nii nagu see päritolumaal sündis. Nii või teisiti on selliste glokaliseerumisprotsesside analüüsides aktsent pingetel või konfliktidel kohaliku kultuuri normide ja väärtustega. Nii süüdistati varast reivikultuuri Venemaal narkootikumide propageerimises (Yurchak 1999), punki Indoneesias moslemikultuuri normide rikkumises (Hannerz 2015; Wallach 2008), Mongoolia hiphoppi liigses läänelikkuses (Marsh 2010) ning seda rida võiks jätkata. Vähe sellest, paljudel juhtudel teevad mandri-Euroopa, Aasia, Aafrika ja Ladina-Ameerika artistid ingliskeelset muusikat, mis on nii äravahetamiseni sarnane selle USA ja briti eeskujudega, et raske on isegi aru saada, et tegemist pole briti või ameerika artistiga. Brent Luvaas (2009) 
peab seda muusikaliseks deterritorialiseerumiseks, millel on kaks eesmärki: olla osa globaalsest skeenest ja usk sellesse, et selline "autentsus" võib aidata artisti alustada edukat rahvusvahelist karjääri.

Muidugi on olemas ka vastupidiseid näiteid, kui näiteks rokkmuusika on muutunud piirkondlikke patriootilisi ideid kandvaks nähtuseks (Friedman \& Weiner 1999; Gudmundsson 1993; Regev 2007; Stankovic 2001), ent see tõik ei ole vähendanud kriitikat selle kohta, et globaalne popkultuur on hävitanud või hävitamas rahvuslikku omapära ning kohalikku kultuurilist ehedust (vt kasvõi jakuudi intelligentide kaebeid hiphopi teemal Iakovleva 2010).

\section{Diskussioon ja järeldused}

2018. aasta novembrikuu alguses Eesti Kirjandusmuuseumi korraldatud doktorantide sügiskoolis Kubijas mängisin auditooriumile ette mitu videoklippi ja palusin osalejatel ära arvata, kust on pärit ettemängitud artistid. Esimene oli punkansambel Casualities looga "Corazones Intoxicados". Tegemist oli klipiga nende Equito kontserdist. Klipis näidatakse tüüpilisi Ladina-Ameerika punkareid, laulja laulab hispaania keeles. Minu küsimusele, kust on pärit see bänd, pakuti erinevaid Ladina-Ameerika maid, ent tegelikult on tegemist punkbändiga New Yorgist ja selle laulja kohta kasutatakse USAs terminit hispanics - hispaaniakeelne ameeriklane. Teine ettemängitud videoklipp oli ansambel Evil Conduct looga "Home, Sweet Home". Videos näidatakse kolme skinheedi väga inglaslikus pubis õlut joomas, kõndimas mööda linna ja muidugi ka muusikat mängimas. Laulja laulab inglise keeles briti aktsendiga ja mitte miski ei reeda, et Evil Conduct on tegelikult hollandi ansambel. Kolmas näide oli kollektiiv nimega Mocca, looga "The best thing". Tegemist on meloodilise indirokiga, mida esitavad asiaatidest muusikud laulavad veatu ameerika inglise aktsendiga. Sel korral pakuti juba täpsemalt, nimelt oletas üks kuuljatest, et tegemist on Filipiinide kollektiiviga. Tegelikult on Mocca Indoneesia üks olulisemaid indiebände. Sealjuures ei näita videos peale füüsilise välimuse miskit bändi Aasia päritolu - video on üles võetud 1930. aastate stiilis väga euroopalikus majas, mis võiks asuda nii USAs kui ka Suurbritannias. Need ja muud videod justkui demonstreeriksid, et kartused on saanud tõeks, ning globaalse (angloameerika) popkultuuri pealetung on viinud lokaalse kultuuri nivelleerumiseni ning enam pole vahet, kus maailma otsas muusikat tehakse, sest kõik artistid kopeerivad ühtesid ja samu oma stiili standardeid.

Subkultuuride sotsioloogia on üldiselt ignoreerinud rahvuslike iseärasuste ning normide ja väärtuste kaasamist glokaliseeruvatesse subkultuuridesse, hilisemad teoreetilised koolkonnad on neid suisa eitanud. Kui juttu tuleb mitte- 
subkultuurilistest väärtustest, siis enamasti on tegu etniliste, kultuuriliste või rassiliste vähemustega, kes läbi muusika protestivad diskrimineerimise vastu (Alexander 2000; Bennett 1999; Dunn 2016; Wade 1999). Niimoodi jääbki mulje, et glokaliseerunud subkultuurid on justkui väljund inimestele, et "astuda välja" oma kultuurist. Teatud mõttes see ongi nii. Noorte subkultuurid pakuvad osalejatele alternatiivset identiteeti, tunnet, et ollakse globaalse skeene osa ja solidaarsustunnet oma mõttekaaslastega. Teisalt ei tähenda see, et rahvuslikud ning lokaalsed aspektid ei eksisteeri kohalikul tasandil globaalse subkultuuri sees. Väga hea näide on kasvõi indoneesia punk. Oma uurimuses väidab Erik Hannerz, et indoneesia punkarid on pidevas konfliktis ümbritseva moslemiühiskonnaga, mille tavadele ja normidele nende käitumine, muusika ning välimus ei vasta (Hannerz 2015). Ajakirja Vice videokanali Noisey tehtud dokumentaalfilmis "Punk Rock vs Sharia Law" väidavad aga noored indoneesia punkarid, et nad peavad ennast moslemiteks, järgivad ka islami reegleid, ent on fundamentaalse islami vastu, mis üritab ette kirjutada, mida ja kuidas nad peavad tegema ${ }^{3}$. See on suurepärane näide sellest, kuidas kohalikud normid ja tavad võetakse kaasa subkultuuri ning need hakkavad mõjutama subkultuurlaste viisi subkultuuri lokaalse vormi kujundamisel.

Kui lugeda kriitilise pilguga subkultuure analüüsivat kirjandust, võib selliseid näiteid leida rohkemgi. Näiteks on varasemad uurijad veendunud, et inglise skinheedide teke on otseselt seotud inglise töölisklassi normide ja väärtuste kandmisega subkultuuri vormi - lokaalsus, maskuliinsus, solidaarsus, aga ka agressiivsus ja alkoholitarbimise idealiseerimine on pärit just sellest keskkonnast (Brake 1974; Clarke 1976). Paul Hodkinsoni uurimuses briti gootikultuurist räägivad osalised selgesõnaliselt, et suurtel festivalidel eelistavad nad inglise gootide seltskonda, sest niimoodi on üksteisemõistmine lihtsam (Hodkinson 2002). Samamoodi on uurijad näidanud, et 1960. aastatel Jamaikal tekkinud rude boy subkultuur oli otseselt seotud saare vaese töölisklassi habitus'e ning esteetiliste arusaamade ühendamisega muusika ning moega (Barrow \& Dalton 1997). Lokaalsete praktikate importi punki on demonstreeritud mitmes uurimuses (Dines \& Gordon \& Guerra 2017; O'Connor 2002, 2004). Sunaina Marr Maira näitab veenvalt, kuidas New Yorgi desi kultuur on kombinatsioon ameerika noortekultuurist ning India, Pakistani ja Bangladeshi konservatiivsest arusaamast soorollide, kombelisuse ning edukuse kohta. Autor näitab ka seda, et desi klubides eksisteerib grupeerumine etnilise printsiibi alusel, kuna Pakistani päritolu noored eelistavad endasarnaste seltskonda India või Bangladeshi noortele ja vastupidi (Maira 2002). Vene skinheede kaua aega uurinud briti teadlane Hilary Pilkington näitab selgelt, kuidas vene proletaarses miljöös eksisteeriv matšokultus, ksenofoobia ja rassism peegelduvad ka skinheedide kommetes (Pilkington 2010, 2014; Pilkington \& Omel'chenko 
\& Garifzianova 2010). Teinekord põimuvad lokaalne ja globaalne ehk siis kohalik väärtussüsteem ja kombestik ning imporditud subkultuur nii tihedalt, et subkultuur peaaegu kaotab rahvusvahelise komponendi. Vene sotsioloog Aleksander Tarassovi uurimused näitavad, et kohalik vene proletaarne gopnikute kultuur ${ }^{4}$ ja transnatsionaalne neonatsistlik parempoolne skinheedikultuur leidsid teineteist suhteliselt kiiresti ja põimusid nii tihedalt, et kultuuriline ja välimuslik erinevus kahe grupi vahel peaaegu kadus. Nii gopnikud kui ka skinheedid olid vägivaldsed rassistid ja ksenofoobid ning sel pinnal tekkis teineteisemõistmine. Uurija väidab, et selline lõimumine on Venemaal unikaalne, sest ükski teine välismaist päritolu subkultuur pole siiani leidnud endale venemaist vastet ega ole sellega kokku kasvanud (Tarasov 2008). Kõige paremini on aga lokaalse väärtussüsteemi eksporti subkultuuri väljendanud hoopis üks kirjanik. John Kingi raamatu "Skinheads" (2009) tegelasteks on kolm põlvkonda inglise skinheede ning raamatu läbiv teema on inglise traditsiooni ja identiteedi üle arutlemine, aga ka selle avalik demonstreerimine. Raamat on väga realistlik, näitab ühtlasi, kuidas rahvuslik ning etniline identiteet ja väärtushinnangud võivad kattuda subkultuuriliste väärtustega sedavõrd, et ühte on teisest võimatu lahutada.

Rahvuslikku subkultuuri on ingliskeelse sõna nation võtmes raske defineerida ja ka teoreetiliselt kontseptualiseerida. Väga paljudel juhtudel näib, et need kaks välistavad teineteist. Näiteks nõukogude vene rokikultuuri on retrospektiivselt kujutatud kui süsteemivastast ja -välist nähtust, mida vastavad nõukogude instantsid ka taga kiusasid ja alla surusid (Cushman 1995; Steinholt 2003; Steinholt \& Wickström 2009; Troitskii 2007; Wickström \& Steinholt 2009). Sellest hoolimata on vähemalt kahes raamatus näidatud, kuidas nõukogudeaegsed vene rokifännid võisid olla samaaegselt siirad kommunistlikud noored (Yurchak 2006) ja nõukogude patrioodid (Smith 1976).

Sellisetele paradoksidele on raske leida ühemõttelist seletust ja alljärgnev on vaid üks võimalikest hüpoteesidest. Minnes tagasi ülalmainitud stiilide supermarketi juurde, võib nentida, et tänapäeval on igal inimesel võimalik valida kümnete subkultuuriliste stiilide vahel. Küsimus on selles, millistest kategooriatest lähtuvalt ta seda teeb. Subkultuur ei ole ainult muusika- ja riietumisstiil, vaid iga stiilipõhise rühmitusega on seotud teatud maailmavaade ja normistik ${ }^{5}$. Miks leiavad vene gopnikud kergesti tee rassistlike neonatsidest skinheedide juurde? Sest skinheadkultuuri ideoloogilised kriteeriumid on neile arusaadavad ja vastuvõetavad. Väga raske on gopnikut ette kujutada hipsteri või hipina, sest nende gruppide maailmavaade on risti vastupidine gopnikute maailmas eksisteerivatele kategooriatele. Olen oma uurimistöös Ida-Saksa punkarite, skinheedide ja jalgpallihuligaanide seas tuvastanud just sellist maaimavaatelist sidet (Ventsel 2008, 2010, 2012; Ventsel \& Araste 2015). 
Sotsialistlik Ida-Saksamaa oli riik, kus proletaarsuse kultus oli enam-vähem riiklik poliitika. Vägivald kui selline polnud taunitud, oli lihtsalt arusaam "õigest" ja "valest" vägivallast. Nii kasutasid ametivõimud kommunistlikest noortest moodustatud vabatahtlikke rühmi, et näiteks suviti ajada laiali parkides aega veetvaid noortejõuke (Fenemore 2007). Seega oli "õige" vägivaldne käitumine riigi poolt sanktsioneeritud. Seoses sellega on idasaksa endiste tööstuslinnade igapäevakultuur väga matšolik ja maskuliinne. Lisaks muule on saksa tööliskultuur ja saksa kultuur ääretult lokaalpatriootlik - inimese regionaalne ning linna- või külaidentiteet on ääretult olulised ja defineerivad tihti tema suhteid ümbritsevaga. Maskuliinsus, agressiivsuse heroiseerimine ja lokaalsus on ka jalgpallihuligaanide ning skinheadkultuuris kesksed ideoloogilised väärtused. Seega juhtubki nii, et endised regionaalsed rivaliteedid ja konfliktid kantakse nüüdisajal välja subkultuuri raames - traditsiooniliselt rivaalitsevatel linnadel on nüüd teineteist vaenavad jalgpallihuligaanide grupid. Jalgpallihuligaanide kultuur annab vanale tavale uue vormi, on selle keeleks, ent mitte loojaks. Nii on Saksamaal legendaarne vastuolu Berliini ja Saksimaa jalgpallifännide vahel, samuti antipaatiad Põhja- ja Lõuna-Saksamaa klubide pooldajate vahel. Iseenesest on siin tegemist regionaalsete konfliktidega, mis lähevad ajaloos tagasi enam kui 200 aastat. Ma olen sama näidanud ka idasaksa streetpungi ja skinheedide kultuuri kohta (Ventsel 2008, 2010, 2012, 2014). Traditsioonilised saksa töölisklassi väärtused nagu autonoomia, lokaalpatriotism, majanduslik sõltumatus ja lojaalsus sõpradele haakuvad subkultuuriliste väärtustega ja nii kujunebki välja rahvuslik subkultuur, antud hetkel näiteks saksa jalgpallihuligaanide kultuur.

On väga erinevaid põhjuseid, miks noor inimene sulandub subkultuuri. Üheks peamiseks mõjutajaks peetakse tema vahetu suhtluskonna (peer group) mõju, aga ka selles seltskonnas eksisteerivaid üldaktsepteeritud norme. Need normid on sageli väga hästi väljendatavad teatud stiilide poolt pakutava keele vahendusel. Nii näiteks näitavad uuringud, et kriminaalsed rühmitused leiavad endale teinekord väljenduse hiphopis (Mullins 2006) kui ka seda et teatud sotsiaalselt marginaliseeritud töölisklassi päritoluga noored loovad endale stiili mis põhineb radikaalsel hiphopil (Martin 2009; McCulloch \& Stewart \& Lovegreen 2006; Nayak 2006; Jones 2011; Young 2013). Teiselt poolt näitavad uuringud, et USA ja briti keskklassi noori tõmbavad subkultuurid, mis seavad esiplaanile kas nohiku elustiili (Bucholtz 2011) või siis eneseväljenduse kunstis (Lamy \& Levin 1985). Need uurimused ei lähe aga enamasti põhjusliku sideme analüüsini - kuidas ja miks emakultuuri väärtused teevad atraktiivseks just teatud stiili. Seega, ühinemine teatud noorte subkultuuriga pole ainult radikaalne emakultuurist väljumine, vaid enesele uue väljendusvormi otsimine, lähtudes emakultuurist pärit maailmavaatest ja normidest. 
Lõpetuseks võib öelda, et teoreetilist arusaama noorte subkultuuridest tuleb revideerida. Praegusel hetkel on subkultuuride uuringutes liiga suur rõhk välisel stiilil ja muusika analüüsil. Kontsentreerides tähelepanu just nendele aspektidele jäävad tihti tähelepanuta need jooned, mis ühendavad subkultuuri oma emaühiskonnaga, mitte ei lahuta teda sellest. Palju rohkem tuleb tähelepanu pühendada fenomeni teisele küljele: subkultuur pakub keele ja vormi, mida täidetakse kohaliku sisuga. Selline lähenemine erineb tavapärasest arusaamast glokaliseerumisele kui globaalse fenomeni mugandumist lokaalsetesse oludesse. Me teame väga vähe sellest, kuidas ühesuguse välimusega ja kohati isegi üht ja sama muusikat tarbivad ja sarnast muusikat tegevad subkultuurid erinevad sisuliselt.

\section{Kommentaarid}

1 Artikkel põhineb ettekandel "Can we talk about national subcultures?: Music, style, networking and alcohol", mille pidasin Eesti Kirjandusmuuseumi korraldatud doktorantide sügiskoolis "Dialoogid laste ja noortega" 1.-2. novembril 2018 Kubija hotellis Võrus. Artikkel on valminud Haridus- ja Teadusministeeriumi uurimisprojekti IUT 34-32 ("Kultuuripärand kui ühiskondlik-kultuuriline ressurss ja probleemne valdkond") raames.

2 Pärast Teist maailmasõda võib täheldada noorte subkultuuride arengus teatud lineaarsust - subkultuurid ilmusid kronoloogiliselt. 1950. aastatel tekkisid teddy boy'd, 1960. aastate alguses modernistid ehk mods ja rokkerid ehk rockers, 1960. aastate keskel ja lõpus oli lühike skinheadide esimene laine, 1970. aastate alguses transformeerusid jamaika rude boy'd rastadeks, 1970. aastate keskel tekkis punk. 1970. aastate lõpus läheb pilt segaseks muuhulgas seoses mitmete subkultuuride nagu skinheedid ja modernistid revival-lainetega. Ainuke sel perioodil globaalset mõju avaldanud USAst pärit noorte subkultuur oli hipid. 1980. aastate algusest võib täheldada uute subkultuuride teket paralleelselt juba eksisteerinud subkultuuride regulaarse tagasitulekuga.

${ }^{3} \mathrm{https} / / / \mathrm{www}$. youtube.com/watch?v=6Sbne-qCNzU\&t=748s (vaadatud 11.07.2019).

${ }^{4}$ Gopnikuteks nimetatakse vene kultuuris väga spetsiifilist töölisnoorte gängikultuuri. Gopnikud kannavad enamasti odavaid spordirõivaid, nokkmütse ja kuldkette. Nad paistavad silma agressiivse käitumisega ning on sageli väga kriminaalsed. Üldjuhul kuulavad nad odavat popmuusikat või spetsiifilisi elektroonilise muusika stiile nagu hard bass.

5 Subkultuurilise käitumisega on seotud ka teatud situatiivsus. Jalgpallihuligaan võib olla hea isa ja death metali austaja töötada vägagi rahulikul kontoritööl. Siia lisandub subkultuuride kommertsialiseerimine moetööstuse poolt. Seda juhtus 1990. aastail grungega ja 2000 aastate alguses pungiga, kui disainermoefirmad hakkasid neid stiile kasutama kallite rõivakollektsioonide tootmisel. See kõik on muidugi tõstatanud subkultuurisiseseid diskussioone selle üle, mis on "päris" ja mis mitte. 


\section{Kirjandus}

Alexander, Claire E. 2000. The Asian Gang. Ethnicity, Identity, Masculinity. New York \& Oxford: Berg.

Allaste, Airi-Alina (koost \& toim) 2013. Subkultuurid: Elustiilide uurimused. Tallinn: TLÜ Kirjastus.

Amico, Stephen 2009. Visible Difference, Audible Difference: Female Singers and Gay Male Fans in Russian Popular Music. Popular Music and Society 32 (3), lk 351-370 (doi: 10.1080/03007760902985809).

Barrow, Steve \& Dalton, Peter 1997. Reggae. The Rough Guide. The Definitive Guide to Jamaican Music, from Ska through Roots to Ragga. London \& New York: The Rough Guides, Penguin Books.

Becker, Howard S. 1997. Outsiders. Studies in Sociology of Deviance. New York: Free Press.

Bennett, Andy 1999. Hip hop am Main: the localization of rap music and hip hop culture. Media Culture Society 21 (1), lk 77-91 (doi: 10.1177/016344399021001004).

Bennett, Andy 2004. Virtual Subculture? Youth, Identity and the Internet. Bennett, Andy \& Kahn-Harris, Keith (toim). After Subculture. Critical Studies in Contemporary Youth Culture. London \& New York: Palgrave Macmillan, lk 162-172 (doi: 10.1007/9780-230-21467-5_12).

Bennett, Andy 2006. Punk's Not Dead: The Continuing Significance of Punk Rock for an Older Generation of Fans. Sociology 40 (219), lk 219-235 (doi: 10.1177/0038038506062030).

Bennett, Andy 2011. The post-subcultural turn: some reflections 10 years on. Journal of Youth Studies 14 (5), lk 493-506 (doi: 10.1080/13676261.2011.559216).

Blackman, Shane 2005. Youth Subcultural Theory: A Critical Engagement with the Concept, its Origins and Politics, from the Chicago School to Postmodernism. Journal of Youth Studies 8 (1), lk 1-20 (doi: 10.1080/13676260500063629).

Bloch, Alexander \& Niederhoffer, Arthur 1958. The Gang. A Study in adolescent Behaviour. New York: Philosophical Library.

Brake, Michael 1974. The Skinheads: An English Working Class Culture. Youth \& Society 6 (2), lk 179-200 (doi: 10.1177/0044118X7400600203).

Brake, Michael 1985. Comparative Youth Culture: The Sociology of Youth Cultures and Youth Subcultures in America, Britain, and Canada. London \& New York: Routledge \& Keagan Paul Ltd.

Bucholtz, Mary 2011. White Kids. Language, Race and Styles of Youth Identity. Cambridge \& New York \& Melbourne \& Madrid \& Cape Town \& Singapore \& Sao Paolo \& Delhi \& Dubai \& Tokyo \& Mexoco City: Cambridge University Press.

Burt, Callie H. \& Simons, Ronald L. 2013. Self-Control, Thrill Seeking, and Crime: Motivation Matters. Criminal Justice and Behavior 40 (11), lk 1326-1348 (doi: 10.1177/0093854813485575). 
Clarke, John 1976. The Skinheads and the Magical Recovery of Community. Hall, Stuart \& Jefferson, Tony (toim). Resistance Through Rituals. Youth Subculture in Post-War Britain. London: Hutchinson, lk 99-102.

Clarke, John \& Critcher, Chas \& Johnson, Richard (toim) 1979. Working-Class Culture. Studies in history and theory. London \& Melborne \& Sydney \& Auckland \& Johannesburg: Hutchinson.

Cohen, Albert K. 1955. Delinquent boys: the culture of the gang. Glencoe(Ill.): Free Press.

Cressey, Paul Goalby 1932. Taxi-Dance Hall. A Sociological Study in Commercialized Recreation and City Life. Chicago: University of Chicago Press.

Cushman, Thomas 1995. Notes from Underground. Rock Music Counterculture in Russia. Albany: State University of New York.

Davis, Joanna R. 2012. Punk, Ageing and the Expectations of Adult Life. Bennet, Andy \& Hodkinson, Paul (toim). Ageing and Youth Cultures. Music, Style and Identity. London \& New York: Berg, lk 105-118 (doi: 10.5040/9781474214223.ch-008).

Dines, Mike \& Gordon, Alastair 'Gords' \& Guerra, Paula (toim) 2017. The Punk Reader. The Research Transmission from the Local to the Global. Porto: University of Porto.

Dunn, Kevin 2016. Global Punk: Resistance and Rebellion in Everyday Life. New York, NY, USA: Bloomsbury.

Fenemore, Mark 2007. Sex, Thugs and Rock'n'Roll. Teenage rebels in Cold-War East Germany. New York, Oxford: Berghahn.

Friedman, Julia P. \& Weiner, Adam 1999. Between A Rock and Hard Place: Holy Rus' and its Alternatives in Russian Rock Music. Barker, Adele Marie (toim). Consuming Russia. Popular Culture, Sex, and Society since Gorbatchev. Durham, London: Duke University Press, lk 110-137 (doi: 10.1215/9780822396413-005).

Frith, Simon 1983. Sound Effects: Youth, Leisure and the Politics of Rock'n'Roll. London: Routledge.

Frith, Simon 1988. Music for Pleasure: Essays in the Sociology of Pop. Vol. Cambridge: Polity Press.

Frith, Simon 2001. The popular music industry. Frith, Simon \& Straw, Will \& Street, John (toim). The Cambridge Companion to Pop and Rock. Cambridge University Press, lk 26-52 (doi: 10.1017/CCOL9780521553698.004).

Garšnek, Igor 2010. Ruja: Must ronk või valge vares. Tallinn: Pegasus.

Gudmundsson, Gestur 1993. Icelandic rock music as a synthesis of international trends and national cultural inheritance. Young 1 (2), lk 48-63 (doi: 10.1177/110330889300100204).

Gusfield, Joseph R. 1995. Moral Passage: The Symbolic Process in Public Designations of Deviance. Macaulay, Stuart \& Friedman, Lawrence Meir \& Stookey, John (toim). Law and Society: Readings on the Social Study of Law. New York \& London: W.W. Norton \& Company, lk 509-521.

Hall, Stuart \& Jefferson, Tony (toim) 1986. Resistance Through Rituals: Youth Subcultures in Post-War Britain. London: Hutchinson. 
Hannerz, Erik 2015. Performing Punk. New York: Palgrave Macmillian.

Hebdige, Dick 1979. Subculture: The Meaning Of Style. New York: Methuen.

Hebdige, Dick 1987. Cut'N'Mix. Culture, Identity and Carribean Music. London and New York: Routledge.

Hesmondhalgh, David 2005. Subcultures, Scenes or Tribes? None of the Above. Journal of Youth Studies 8 (1), lk 21-40 (doi: 10.1080/13676260500063652).

Hodkinson, Paul 2002. Goth. identity, Style and Subculture. Oxford \& New York: Berg.

Hodkinson, Paul 2011. Ageing in a spectacular 'youth culture': continuity, change and community amongst older goths. The British Journal of Sociology 62 (2), lk 262-282 (doi: 10.1111/j.1468-4446.2011.01364.x).

Iakovleva, Arina 2010. Andrei Borisov: marginaly vsekh stran, soediniaites'! Yakutsk Vechernii, 20.08.

Jones, Owen 2011. Chavs: The Demonization of the Working Class. London: Verso Books. King, John 2009. Skinheads. London: Vintage.

Lamy, Philip \& Levin, Jack 1985. Punk and Middle-Class Values: A Content Analysis. Youth \& Society 17 (2), lk 157-170 (doi: 10.1177/0044118X85017002003).

Luvaas, Brent 2009. Dislocating Sounds: The Deterritorialization of Indonesian Indie Pop. Cultural Anthropology 24 (2), lk 246-279 (doi: 10.1111/j.1548-1360.2009.01131.x).

Macilwee, Michael 2015. The Teddy Bow Wars. The Youth Cult That Shocker Britain. Croydon: Milo Books LTD.

Maira, Sunaina Marr 2002. Desis in the house. Indian American Youth Culture in new York City. Philadelphia: Temple University Press.

Marcus, Greil 1989. Lipstick Traces: A Secret History of the Twentieth Century. London: Faber and Faber.

Marsh, Peter K. 2010. Our generation is opening its eyes: hip-hop and youth identity in contemporary Mongolia. Central Asian Survey 29 (3), lk 345-358 (doi: 10.1080/02634937.2010.518013).

Martin, Greg 2009. Subculture, style, chavs and consumer capitalism: Towards a critical cultural criminology of youth. Crime Media Culture 5 (2), lk 123-145 (doi: 10.1177/1741659009335613).

McCulloch, Ken \& Stewart, Alexis \& Lovegreen, Nick 2006. 'We just hang out together': Youth Cultures and Social Class. Journal of Youth Studies 9 (5), lk 539-556 (doi: 10.1080/13676260601020999).

Muggleton, David (toim) 2000. Inside Subculture. Oxford, New York: Berg.

Muggleton, David 2005. From classlessness to clubculture: A genealogy of post-war British youth cultural analysis. Young 13 (2), lk 205-219 (doi: 10.1177/1103308805051322).

Muggleton, David \& Weinzierl, Rupert (toim) 2003. The post-subcultures reader. Oxford $\&$ New York: Berg.

Mullins, Christopher W. 2006. Holding Your Square. Masculinities, Streetlife and Violence. Cullompton (Devon) \& Portland (Oregon): William Publishing. 
Nayak, Anoop 2003. Race, Place and Globalization: Youth Cultures in a Changing World. Oxford \& New York: Berg.

Nayak, Anoop 2006. Displaced Masculinities: Chavs, Youth and Class in the Postindustrial City. Sociology 40 (5), lk 813-831 (doi: 10.1177/0038038506067508).

O'Connor, Alan 2002. Local scenes and dangerous crossroads: punk and theories of cultural hybridity. Popular Music 21 (2), lk 225-236 (doi: 10.1017/S0261143002002143).

O'Connor, Alan 2004. Punk and globalization. Spain and Mexico. International Journal of Cultural Studies 7 (2), lk 175-195 (doi: 10.1177/1367877904044252).

Pilkington, Hilary 2010. No Longer "On Parade": Style and the Performance of Skinhead in the Russian Far North. The Russian Review 69, lk 187-209 (doi: 10.1111/j.14679434.2010.00562.x).

Pilkington, Hilary 2014. 'My Whole Life Is Here': Tracing Journeys through 'Skinhead'. Buckingham, David \& Bragg, Sara \& Kehily, Mary Jane (toim). Youth Cultures in the Age of Global Media. New York: Palgrave Macmillan, lk 71-87.

Pilkington, Hilary \& Omel'chenko, Elena \& Garifzianova, Al'bina (toim) 2010. Russia's Skinheads. Exploring and rethinking subcultural lives. London, New York: Routledge.

Polhemus, Ted 1997. In the Supermarket of Style. Redhead, Steve \& Wynne, Derek \& O'Connor, Justin (toim). The Clubcultures Reader: Readings in Popular Cultural Studies. Oxford \& Malden: Wiley-Blackwell, lk 130-132.

Regev, Motti 2007. Ethno-National Pop-Rock Music: Aesthetic Cosmopolitanism Made from Within. Cultural Sociology 1 (3), lk 317-341 (doi: 10.1177/1749975507082051).

Rinne, Harri 2009. Laulev revolutsioon: Eesti rokipõlvkonna ime. Tallinn: Varrak.

Salumets, Vello 1998. Rockrapsoodia. Tallinn: Eesti Entsüklopeediakirjastus.

Salumets, Vello 2010. Fikseeritud Fix. Tallinn: Greif.

Sampson, Robert J. \& Bartusch, Dawn Jeglum 1988. Legal Cynicism and (Subcultural?) Tolerance of Deviance: The Neighborhood Context of Racial Differences. Law \& Society Review 32 (4), lk 777-804 (doi: 10.2307/827739).

Savage, Jon 2007. Teenage. The Creation of Youth 1875-1945. London: Chatto \& Windus.

Savigliano, Marta E. 1995. Tango and the Political Economy of Passion. Boulder, Oxford: Westview.

Shildrick, Tracy 2006. Youth culture, subculture and the importance of neighbourhood. Young 14 (1), lk 61-74 (doi: 10.1177/1103308806059815).

Shildrick, Tracy \& MacDonald, Robert 2006. In Defence of Subculture: Young People, Leisure and Social Divisions. Journal of Youth Studies 9 (2), lk 125-140 (doi: 10.1080/13676260600635599).

Smith, Hedrick 1976. The Russians. New York: Ballantine Books.

Stankovič, Peter 2001. Appropriating 'Balkan': Rock and Nationalism in Slovenia. Critical Sociology 27 (3), lk 98-115 (doi: 10.1177/08969205010270030501, $10.1163 / 156916301320250303)$. 
Steinholt, Yngvar B. 2003. You can't rid a song of its words: notes on the hegemony of lyrics in Russian rock songs. Popular Music 22 (1), lk 89-108.

Steinholt, Yngvar B. \& Wickström, David-Emil 2009. Introduction. Popular Music and Society 32 (3), lk 307-311.

Straw, Will 2002. Scenes and Sensibilities. Public 22/23, lk 245-257.

Tarasov, Aleksandr 2008. Changing Subcultures: Observations on Skinheads. Russian Politics and Law 46 (1), lk 31-49 (doi: 10.2753/RUP1061-1940460103).

Troitskii, Artemii 2007. Back in the USSR. Sankt-Peterburg: Amfora.

Tõnson, Helga 1976. Georg Ots. Tallinn: Eesti Raamat.

Vahter, Tarmo 2015. “Karuks istus vangitornis...”. 1980 - aasta, mis raputas Eestit. Tallinn: OÜ Hea Lugu.

Ventsel, Aimar 2008. Punx and Skins United: One Law For Us One Law For Them. Journal of Legal Pluralism 57, lk 45-100 (doi: 10.1080/07329113.2008.10756618).

Ventsel, Aimar 2010. "Our beer is better than theirs": Sub-cultural comics as a Joking Relationship with identity. Folklore: Electronic Journal of Folklore 46, lk 143-160 (doi: 10.7592/FEJF2010.56.ventsel).

Ventsel, Aimar 2012. This is not my country, my country is the GDR: East German punk and socio-economic processes after German reunification. Punk \& Post Punk 1 (3), lk 343-359 (doi: 10.1386/punk.1.3.343_1).

Ventsel, Aimar 2014. "That Old School Lonsdale": Authenticity and Clothes in Streetpunk and Skinhead Culture. Cobb, Russell (toim). The Paradox of Authenticity in a Globalized World. New York: Palgrave MacMillan, lk 261-276.

Ventsel, Aimar \& Araste, Lii 2015. They have no right to wear those clothes: The ambivalence of the dress code of German skinheads and Estonian metal heads. Fashion, Style \& Popular Culture 2 (2), lk 257-272 (doi: 10.1386/fspc.2.2.257_1).

Wade, Peter 1999. Working Culture. Making Cultural Identities in Cali, Columbia. Current Anthropology 40 (4), lk 449-470 (doi: 10.1086/200045).

Wallace, Claire \& Alt, Raimund 2001. Youth Cultures under Authoritarian Regimes: The Case of the Swings Against Nazis. Youth \& Society 32, lk 275-302 (doi: 10.1177/0044118X01032003001).

Wallach, Jeremy 2008. Living the Punk Lifestyle in Jakarta. Ethnomusicology 52 (1), lk 99-116.

Whyte, William Foote 1998. Street Corner Society. The Social Structure of an Italian Slum. Chicago and London: The University of Chicago Press.

Wickström, David-Emil \& Steinholt, Yngvar B. 2009. Visions of the (Holy) Motherland in Contemporary Russian Popular Music: Nostalgia, Patriotism, Religion and Russkii Rok. Popular Music and Society 32 (3), lk 313-330 (doi: 10.1080/03007760902985668).

Williams, J. Patrick 2006. Authentic Identities: Straightedge Subculture, Music, and the Internet. Journal of Contemporary Ethnography 35 (2), lk 173-200 (doi: 10.1177/0891241605285100). 
Willis, Paul 2000. Learning to labour: how working class kids get working class jobs. Ashgate: Aldershot.

Willis, Paul \& Jones, Simon \& Canaan, Joyce \& Hurd, Geoff 1990. Common Culture. Symbolic Work At Play In The Everyday Cultures Of The Young. Milton Keynes: Open University Press.

Wolfgang, Marvin E. \& Ferracuti, Franco 1982. The subculture of violence: towards an integrated theory in criminology. Thousand Oaks: Sage Publishers.

Yablonsky, Lewis 1962. The Violent Gang. New York: The Macmillan Company.

Young, Robert 2013. Can Neds (or Chavs) Be Non-delinquent, Educated or Even Middle Class? Contrasting Empirical Findings with Cultural Stereotypes. Sociology 10 (6), lk 1140-1160 (doi: 10.1177/0038038511435059).

Yurchak, Alexei 1999. Gagarin and the Rave Kids: Transforming power, identity, and aesthetics in the post-Soviet nightlife. Barker, Adele Marie (toim). Consuming Russia: Popular Culture, Sex, and Society Since Gorbachev. Durham, London: Duke University Press, lk 77-109.

Yurchak, Alexei 2006. Everything Was Forever, Until It Was No More: The Last Soviet Generation. Princeton \& Oxford: Princeton University Press.

\title{
Summary
}

\section{Are there any reasonable grounds for speaking about national subcultures?}

\author{
Aimar Ventsel \\ Senior Research Fellow \\ Department of Ethnology, University of Tartu \\ aimar.ventsel@ut.ee
}

Keywords: glocalisation, hip-hop, identity, punk, skinhead, subculture, working class

General interpretation of youth subcultures often largely ignores the national element, and in case it is included at all, then only in the framework of local changes in global music or style or cultural and social conflicts. However, my focus in this article lies on studying Germanness in the abovementioned subcultures. I argue that punk and skinhead culture is suited for the working class rebellion because it largely overlaps with the notion of local patriotism in Germany. When looking at the cult of locality in German punk music or loyalty to local and regional beer, this is something that one can also observe among non-subculture individuals. The article exemplifies how the multitude of subcultural styles supports certain anti-glocalisation trends, and how music, style, and alcohol are used to express genuine working class values, political views, and identity concepts. 